\title{
Fratura bilateral em epífise femoral proximal em uma vaca Holandesa
}

\author{
Bilateral fracture in the proximal femoral epiphysis in a Holstein cow
}

Bruno Inácio Correa de Oliveira, Ligia Valéria Nascimento*, Rüdiger Daniel Ollhoff

Pontifícia Universidade Católica do Paraná (PUCPR), Curitiba, PR, Brasil

\section{Resumo}

Apesar do aumento expressivo das pesquisas em ortopedia veterinária, principalmente voltadas à podologia do locomotor distal, as fraturas em grandes animais são um constante desafio para o médico veterinário. Em relação às afecções do locomotor proximal, pouco se tem publicado principalmente na literatura nacional. 0 objetivo deste trabalho foi relatar um caso de fratura em ambas as epífises proximais do fêmur de uma vaca Holandesa, primípara, lactante, com 29 meses de idade, criada em sistema de estabulação livre (free-stall). As fraturas foram do tipo I de Salter-Harris . A causa foi uma excessiva força atribuída sobre o fêmur, provocada por uma queda, após aceitação de monta, em piso escorregadio no momento do retorno da sala de ordenha. Os achados clínicos e anátomopatológicos foram evidenciados. A importância de um diagnóstico ágil e tomada de decisão rápida foram ressaltados para minimizar o sofrimento do animal.

Palavras-chave: Ortopedia. Fratura. Salter-Harris. Achados clínicos e anátomopatológicos.

\begin{abstract}
Despite the significant increase in research in veterinary orthopedics, specially directed to the distal locomotor system and podology, fractures in large animals continue to be a challenge for the field veterinarian. Consideri9ng the proximal locomotor system, literature in general and mainly national literature is scarce. The objective of this study was to report a case of two proximal epiphysis Salter-Harris type I fractures of the femur. The animal was a Holstein cow, primiparous, lactating, with 29 months of age, created under free stall system. The cause an excessive force attributed on the femur due to a fall, after acceptance of mounts on slippery floor at the time of return from the milking parlor.The clinical and pathological findings were described. The importance of agile diagnosis and rapid decision-making were emphasized to minimize animal suffering.
\end{abstract}

Keywords: Orthopedics. Fracture. Salter Harris. Clinical and phatological findings. 


\section{Introdução}

As fraturas em ruminantes são relativamente comuns em vários sistemas de criação, sendo para a pecuária leiteira e de corte um fator de expressivas perdas econômicas. Estas ocorrem normalmente em animais jovens, oriundas de traumas por distocia, auxílio obstétrico errôneo e com uso excessivo da força, ou pisoteio da mãe, sendo as mais observadas em ossos longos, presentes no esqueleto apendicular (Spadeto Jr et al., 2010; Mulon, 2013; Camara et al., 2014). As fraturas podem ser classificadas basicamente em completas ou incompletas, podendo ser abertas ou fechadas, de acordo com a exposição ao meio externo, transversas, oblíquas, em espiral, cominutivas (redutível e não redutível) ou múltiplas, considerando a direção da linha de fratura (St Jean et al., 2014).

As fraturas coxofemorais, apesar de mais raras em animais adultos, representam um desafio para o médico veterinário no diagnóstico e tratamento, pelo fato da região anatômica estar encoberta pela musculatura glútea, o que dificulta a palpação e a inspeção no exame físico (Marchionatti et al., 2014). 0 uso da radiografia ainda é raro, sob condições de campo brasileiros, assim como a ausência de probes de 3,5 MHz na ultrassonografia, capazes de atingir profundidades necessárias para a representação de estruturas ósseas relacionadas à pelve e fêmur (Cholfe, 2015).

As práticas de manejo em pisos escorregadios, lotes de animais heterogêneos em diferentes tamanhos ou idades, e temperamento são considerados fatores predisponentes para a ocorrência de fraturas. No tocante, a ocorrência de fraturas em ossos vertebrais acontece em grande parte durante a manifestação do estro e em vacas com cistos ovarianos, quando montadas por animais em ambientes semelhantes ou ainda por animais mais pesados (Braun et al., 2017; Delfiol et al., 2009).

Em geral, as fraturas evoluem com sinais clínicos agudos. Contudo, os sinais clínicos são variáveis, dependendo da sua localização, severidade e ocorrência de compressão medular, além do envolvimento de grandes nervos (Afonso et al., 2011).

\section{Relato de caso}

Uma vaca Holandesa, primípara, 29 meses de idade, $710 \mathrm{~kg}$, lactante em regime de criação intensivo sob estabulação livre (free-stall), sob piso ripado, havia sido submetida recentemente a um protocolo de inseminação artificial em tempo fixo - ITAF. No $10^{\circ}$ dia do protocolo, em fase de estro, aceitou monta no retorno da sala de ordenha. 0 impacto da monta por outra vaca levou a uma queda. A vaca permaneceu em decúbito esternal sem a possibilidade de se levantar mesmo após sucessivas tentativas e com o auxílio de duas pessoas. Ao exame clínico, os dois membros pélvicos se encontravam em posição de abdução, com a tíbia paralela à coluna vertebral e o calcâneo em um ângulo de 90 graus com relação à mesma (Figura 1). A temperatura retal estava ligeiramente elevada $\left(39,7^{\circ} \mathrm{C}\right)$, frequência cardíaca de 120 batimentos por minuto (bpm), frequência respiratória de 30 respirações por minuto, e rúmen com dois movimentos ruminais em cinco minutos.

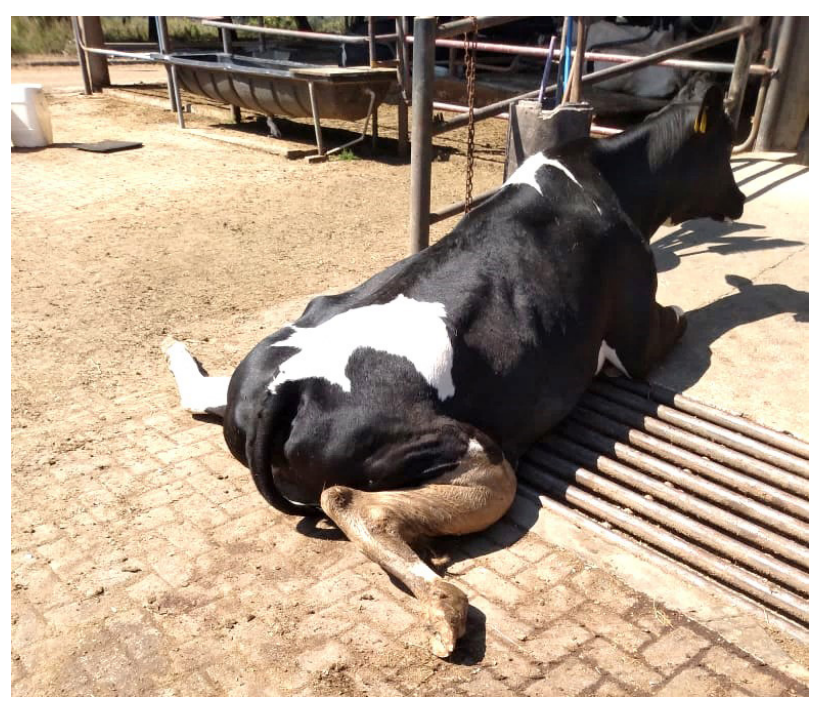

Figura 1 - Animal no retorno da ordenha em decúbito esternal, com os membros pélvicos distendidos lateralmente, apresentando fratura bilateral em epífise proximal no eixo femoral (linha de crescimento).

A vaca também apresentou bruxismo. 0 exame neurológico não evidenciou comprometimento encefálico e de nervos cranianos. 0 exame de sensibilidade cutânea na linha média do dorso 
revelou reflexos até a região de osso sacral, porém em região distal dos membros pélvicos esta sensibilidade estava ausente. A palpação de ambos os membros pélvicos revelou um aumento de volume e importante desconformidade em região da articulação coxofemoral, quando do deslocamento cranial à fossa do acetábulo, assim como na auscultação, onde ouviram-se crepitações quando da movimentação passiva do membro. A palpação retal da sínfise pélvica não revelou fratura.

Ao finalizar o exame clínico, o quadro apresentado sugeriu a existência de uma fratura bilateral do fêmur, com possível compressão do $N$. obturatorius. Mediante à situação de extrema dor e da impossibilidade material de se proceder uma cirurgia ortopédica, optou-se pela realização da eutanásia.

Foi observado durante a necropsia, hematoma em musculatura glútea nos dois membros próximo à região da fratura, duas fraturas nas regiões epifisárias, Salter-Harris do tipo I (fratura por arranquio) no eixo femoral de ambos os membros pélvicos, separando a cabeça do fêmur da mesma (Figura 2). Não houve outros achados na necropsia.
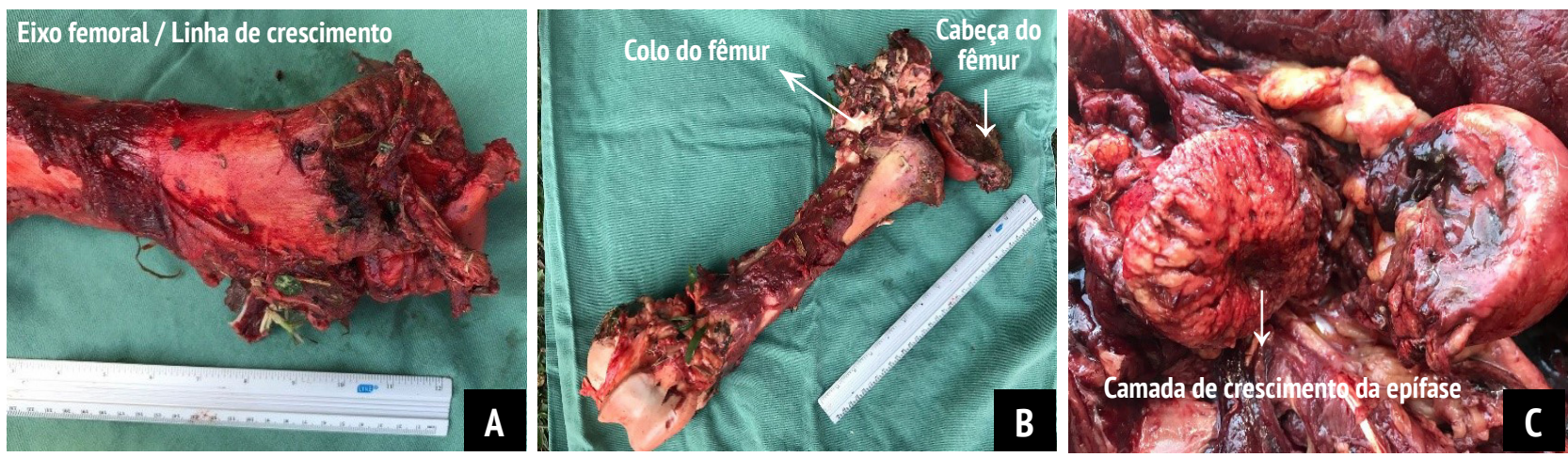

Figura 2 - (A) Vista caudo-medial do osso femur de membro pélvico esquerdo mostrando completo arranquio da cabeça do fêmur na linha epifisária. Vista cranial (B) e dorsolateral (C) do osso fêmur do membro pélvico direito com fratura em eixo femoral, com a presença da cabeça do fêmur ligada somente por restos da cápsula articular.

\section{Discussão}

Com o animal em decúbito esternal e os membros distendidos lateralmente, a avaliação clínica indicava alteração em região coxofemoral. Para Marchionatti et al. (2014), o exame clínico pode ser feito com o animal em pé ou em decúbito lateral. Em estação, deverá ser palpado o trocânter maior com o membro suavemente abduzido, no entanto, dependendo do tamanho do animal, esta manipulação pode ser impossível de ser realizada, mas se houver crepitação, a luxação ou fratura poderá ser suspeitada. Um exame musculoesquelético completo pode ser realizado, além da possibilidade de avaliação via transretal, que eventualmente indicará luxação ou fratura por meio da palpação da cabeça do fêmur.
Através da necropsia, confirmou-se fratura bilateral em cabeça do fêmur, com comprometimento articular, tendíneo e evidente hematoma ocorrido por traumatismo devido à aceitação de monta por outro animal. Semelhante trabalho foi publicado por Delfiol et al. (2009), que concluíram o diagnóstico de fratura por traumatismo em processo espinhoso, revelada pela presença de focos hemorrágicos indicativo de traumas resultando em desfragmentação óssea.

As fraturas distais, envolvendo metacarpo e metatarso, são as mais comuns em bovinos, uma vez que a falta de proteção do tecido mole determina maiores índices de traumas externos. As que afetam o fêmur ocorrem em menores quantidades, apresentando prognóstico reservado, porém, em algumas ocasiões, a única opção é a eutanásia, 
considerando que o tratamento conservativo se declara inviável devido à incapacidade de estabilização óssea (Mulon, 2013; Câmara et al., 2014).

O piso cimentado com o uso contínuo pelos bovinos sofre um desgaste, perdendo boa parte de sua abrasividade e se tornando mais liso e escorregadio. 0 cimento no free-stall da leiteria envolvida se encontra em uso contínuo, sem manutenção há 19 anos, o que pode ter contribuído para o acidente.

A prevenção de quedas em vacas adultas passa igualmente por metodologias de manejo inteligente, incluindo a prevenção da ocorrência de alterações metabólicas principalmente no periparto, que podem levar a um prejuízo da locomoção como, por exemplo as hipocalcemias, as cetoses e os partos distócicos (Delfiol et al., 2009).

\section{Conclusão}

O diagnóstico ágil e preciso de condições impossíveis de serem tratadas na clínica buiátrica, como neste exemplo de fratura bilateral da cabeça do fêmur, com tomada de decisão igualmente rápida, é essencial para minimizar prejuízos futuros do proprietário, além de atenuar o sofrimento animal.

\section{Referências}

Afonso JAB, Souto RJC, Silva Filho AP, Coutinho LT, Mendonça CL, Costa NA. Luxação sacroilíaca em vaca Relato de caso. Rev Bras Med Vet. 2011;33(1):29-31.

Braun U, Warislohner S, Hetzel U, Nuss K. Case report: clinical and postmortem findings ins four cows with rib fracture BMC Res Notes. 2017;10(1):85.

Camara ACL, Calado EB, Antunes JMAP, Oliveira CMM, Afonso JAB, Costa NA. Tratamento conservativo cirúrgico em 22 ruminantes com fraturas em membros. Pesq Vet Bras. 2014;34(11): 1045-50.

Cholfe BF. Avaliação ultrassonográfica das articulações femurotibial e femuropatelar em touros atletas [tese]. Botucatu: Univeersidade Estadual Paulista; 2015. 102 p.
Delfiol DJZ, Menarim BC, Noro M. Fraturas de vertebras torácicas em bovinos brangus confinado. Campo digital. 2009;4(1):155-60.

Marchionatti E, Fecteau G, Desrochers A. Traumatic conditions of the coxofemoral joint: luxation, femoral head-neck fracture, acetabular fracture. Vet Clin North Am Food Anim Pract. 2014;30(1):247-64.

Mulon PY. Management of long bone fractures in cattle. In Pract. 2013;35(5):265-71.

Spadeto Jr O, Faleiros RR, Alves GES, Casas EBL, Rodrigues LB, Loiacono BZ, et al. Falhas na utilização de poliacetal e poliamida em forma de haste intramedular bloqueada para imobiliาzação de fratura femural induzida em bovinos jovens. Cienc Rural. 2010;40(4):907-12.

St Jean G, Anderson DE. Decision analysis for fracture management in cattle. Vet Clin North Am Food Anim Pract. 2014;30(1):1-10. 